\title{
Where's morphomics?
}

\author{
Anna M. Thornton \\ Università dell'Aquila \\ annamaria.thornton@univaq.it
}

How to cite: Thornton, Anna M. 2021. Where's morphomics? Isogloss. Open

Journal of Romance Linguistics 7, 19: 1-8.

\section{Introduction}

At a time when the world as I knew it had abruptly changed, when entering a public space with a mask covering your face had become mandatory rather than illegal, when world trade had to operate for a couple of weeks without the Suez Canal which had been there since before all my grandparents were born, I was invited to take part in a completely new enterprise in linguistics too.

Since I found the topic interesting, I innocently accepted Roberta D'Alessandro's invitation to contribute to the present discussion about Michal Starke's view of what both he and the invitation to contribute dub "morphological irregularities". The whole enterprise hurled me into a world that appears to me even stranger than daily life in the time of Covid19.

We were asked to discuss not a paper (let alone a published article), but a conference talk available for view on the web - like many talks given during the pandemic. After a while, the slides presented during the talk were also made available to the contributors, in an un-downloadable format and with unnumbered "pages". So my first problem is how to refer to specific passages of Starke's presentation - referring to the exact minute and second in which something is stated in the video will have to do.

I devised a plan to circumvent the uncertainty I felt about having to discuss the content of what was available only as a video and a slideshow on the web: I thought I would read as many as possible of the author's printed publications on 
the same topic, to get a better grasp of his arguments. I went to Michal Starke's webpage (https://www.muni.cz/en/people/238968-michal-starke) and looked at his list of publications -- thereby encountering a new unexpected obstacle, and a new feature of the different world I was entering: most of the items listed under the heading Publications were classified as "Appeared in Conference without Proceedings", i.e., were conference talks not available in a written version, like the one I started from (and, sadly, there was no link to a video of these other talks). ${ }^{1}$

\section{Same problems, different communities}

My sense of moving in a different world from the one I knew increased as I listened to the NELS talk and looked at the slides; and this brings me to the first observation that might, however obvious, be of some interest to at least some readers. As anyone as old as I am knows very well, different sub-communities in linguistics often operate in a self-referential way, without awareness of, or interest in, how a given topic has been addressed by other sub-communities. It seems to me that Starke's NELS presentation proceeds without any reference to the huge amount of work done on Romance and particularly French verb morphology by the community of morphologists with which I am better acquainted. I am of course not immune to this fault: I have never done any original work in syntax, let alone nanosyntax, and was unaware of how this approach addresses verbal inflection until I watched the video I have been asked to comment upon.

I must state at the very beginning to which sub-community I belong: after an initial training in Saussurean European structuralism, which did not equip me very well for dealing with inflectional morphology, I came to adhere to word and paradigm (Matthews 1991), a-morphous (Anderson 1992) models of morphology, recognizing a level of morphology by itself (Aronoff 1994) and morphological autonomy (Maiden et al. 2011), and adopted an inferential-realizational model of morphological analysis (Stump 2001). All the work by the founding fathers of autonomous morphology just listed, and the main tenets of these approaches, are not mentioned by Starke, even though the topic he addresses has been at the center of interest of most of these scholars, as well as of other scholars that adopt the same approach. In particular, a lot of work has been done on French verb stems (see at least Bonami \& Boyé 2003, 2007, Bonami, Boyé \& Kerleroux 2009). I am less qualified than all the authors just listed, at least some of whom, I am told, were asked to contribute to this discussion, but had to decline for lack of time or inclination to embark in this enterprise. So I took it upon myself to illustrate the reactions that Starke's talk might trigger in a typical adherent of autonomous / a-morphous / inferential-realizational models encompassing morphology by itself as a level of analysis (a level called morphomic by Aronoff 1994).

1 By no means do I want to imply that all the aspects of the "new world" I encountered are negative. I think it is extremely helpful to be able to watch videos of talks given at conferences that many people could not attend, for medical, financial or other reasons (such as a wish not to contribute to pollution through unnecessary air travel). 
Nothing of what I am going to write is new; its interest lies only in the fact that it might be new for readers who have never been exposed to work in the autonomous morphology tradition.

It is possible that I have misunderstood part of Starke's arguments; in the old world, these mistakes might have been pointed out by the journal's reviewers, but still another new feature of the present brave new world is that this reply will not undergo peer review, the editor tells me. So I have no other choice than expose my ignorance in syntactic matters and thereby risk disgracing myself. I apologize in advance for any shortcoming of this kind.

\section{An IA model of morphology}

The model behind Starke's approach seems to be a lexical-realizational one (Stump 2001) ${ }^{2}$ which, in Hockett's (1954) tripartition, would be called and Item and arrangement (IA) model. In an IA model there is no morphology at all, since items (lexical items / morphemes) are put together (i.e., "arranged", in the American structuralist terminology, or "merged", in the recent syntactically oriented parlance) in syntax. In Hockett's characterization of this model, it is openly stated that there is no difference between operations that create words and operations that create phrases or higher syntactic units:

The essence of IA is to talk simply of things and the arrangements in which those things occur [...]. One assumes that any utterance in a given language consists wholly of a certain number of minimum grammatically relevant elements, called morphemes, in a certain arrangement relative to each other. The structure of the utterance is specified by stating the morphemes and the arrangement (Hockett 1954: 212).

The slide that opens at the fifth click in Starke's presentation, and his words at minute $3: 47-3: 54$, state that all we need is "a simple principled universal syntax and a simple principled lexicon" -- strikingly parallel to just items (lexicon) and arrangement (syntax).

As an homage to Michal Starke's fondness for iconic quotations from masters of the past (see his quote from Jespersen at minutes 50:39-50:46), at this point I will quote one of my own favourite iconic quotations about morphemebased (i.e., item-based) models of morphology, from Anderson (1982). Anderson's article starts by recapitulating the place of morphology, and of its fundamental unit, called "word", in early generative grammar; he declares that the problems to be addressed concern the distribution of morphemes and their variation in shape. As far as the distribution is concerned, he observes that "[i]n syntax [...] the principles governing the distribution of significant elements provided no particular justification for limiting their operands to units of (at least) the size of entire words"; "[i]n phonology, the discovery was made that when we extend the scope of rule governed generalizations beyond the particular limits

2 Lexical-realizational models "assume that rules of syntax construct hierarchical combinations of abstract [...] sets of morphosyntactic properties [...] into which concrete formatives are inserted from the lexicon" (Stump 2001: 2). 
imposed [...] by surface contrast, the effect is to increase the range of cases in which variation in shape [...] can be reduced to a single underlying form" (Anderson 1982: 571), thereby ascribing the study of allomorphy to phonology. And here comes my favourite quote:

With neither morpheme distributions nor allomorphy to account for, then, morphologists could safely go to the beach (Anderson 1982: 571).

Most of the work done by the morphologists belonging to the community I have presented above, from Anderson (1982) on, has been devoted to showing that, unfortunately, there is little time left to go to the beach (although we have gone to several ones during day-trips at the end of various Mediterranean Morphology Meetings, and when lacking beaches nearby we have resorted to thermal baths during and after the International Morphology Meetings held in Hungary). The reason is that languages of the world exhibit, both in synchrony and in diachrony, many phenomena that appear to be irreducible to simple principles of morpheme concatenation and phonological alternations. A short but extremely complete review of such phenomena is found in Anderson (2015).

\section{4. "Irregularity" and morphomic regularities}

Starke explicitly does not address phonological issues in his talk, but he does touch upon some of the phenomena that have been at the center of preoccupations of autonomous morphologists, such as stem suppletion. I will comment on this momentarily.

An aspect of Starke's presentation that strikes me as uninformed, to say the least, is his view of what he repeatedly calls "irregularity" (a term which, as already observed, has been adopted also in the call for contributions to the present debate). Starke says (minutes 2:47-4:18; my transcription):

There is no such thing as irregular morphology. Or more precisely there is no such thing as irregularity in the morphological or morphosyntactic system. Take for instance [...] French finite verbs and their suppletive roots. [...] This is the kind of chaos that prompts people to give up on morphology or to do morphology by simply listing irregularity somewhere and then inventing technology to handle those lists: readjustment rules, dedicated morphological modules, rewrite rules, whatever. [...] this irregular morphology which is usually relegated in lists of exceptions is actually going to give us precious clues as to the underlying syntax and about UG itself.

The view of morphology being done by "simply listing" irregularities and "exceptions" seems to me to describe better the approach taken by authors of teaching grammars than that of the morphologists I mentioned above. These scholars indeed share the view that apparent "chaos" or "irregularity" can be analyzed as exhibiting regularity at a different level -- the morphomic level. These regularities emerge clearly if one looks at whole paradigms, rather than at single forms in isolation. The "people" who "give up on morphology" are perhaps syntacticians, but not the morphologists I know. A great amount of work in the 
last 30 years has shown that things such as the distribution of suppletive stems in Latin and Romance verb paradigms do indeed give precious information about universal properties of grammars (even if maybe not about UG proper, as it is commonly understood).

The seminal work by Aronoff (1994) has shown that the distribution of the so-called "third stem" in Latin verb paradigms is not reducible to semantic, syntactic or phonological properties, but is uniform across paradigms, regardless of the phonological makeup of the single third stem in each paradigm (which can range from the perfectly regular laudat- of laudo 'praise' to the outrageously suppletive lat- of fero 'carry'). The parallel distribution of forms based on the third stem (forms which do not share any common morphosyntactic content, besides the verb's lexical meaning) in all Latin verb paradigms regardless of the stem's phonology uncovers the existence of what has been called a morphomic (Aronoff 1994) partition (Pirrelli \& Battista 2000) within Latin verb paradigms.

Maiden (1992, and countless further contributions, culminating in his 2018 book) has shown that the existence of such partitions

can be appreciated not as basically 'inert' deviation from a natural isomorphic relationship between meaning and form, but as an active, abstract structural property of morphological systems. [...] paradigmatic form, abstracted from both the properties it expresses and from its phonological substance, can exercise a kind of diachronic moulding force on morphological structure (Maiden 1992: 285).

Examples of the diachronic moulding force exerted by morphomic properties of paradigms abound in Maiden's work; I will cite only two from my native tongue, Italian.

\subsection{Novel allomorphy}

Maiden (1992: 297-301) shows that "novel allomorphy", not resulting from phonological changes, develops in certain verbs to comply with a paradigmatically conditioned distribution of suppletive stems: for example, the Italian verb fuggire /fud'dzire/ 'flee', which in Old Italian displayed the palatalalveolar affricate /ddz/ throughtout the paradigm, due to regular phonological evolution from Latin FUGIO, later replaced /ddz/ with $/ \mathrm{gg} /$ in certain cells, for no phonological reason, but in order to conform to a stem distribution pattern present in other verbs, such as leggere 'read' < Latin LEGO, in which the alternation between stems displaying / $/ \mathrm{dd}_{3} /$ and stems displaying /gg/ had come about due to differential phonological evolution of Latin /g/ in different environments (and the two stems do not align with coherent sets of morphosyntactic properties of the forms in which they appear). So this stem distribution pattern, far from being just an "irregularity" or "exception", acted as a "moulding force" in diachronic change.

\subsection{Distribution of suppletive stems}

Maiden (1995, 2004 and further work) shows that even incursive suppletion, i.e. the "invasion" of the paradigm of a certain lexeme by forms originally belonging to a different lexeme, is constrained by morphomic partitions. A famous Italian example is that of the verb uscire 'go out, exit' < Latin EXIRE 'id.' The Latin 
etymon yields $/ \varepsilon /$ as the first vowel of the stem, and in no way can it account for the $/ \mathrm{u} /$ we find in most forms of the verb. The presence of $/ \mathrm{u} /$ in forms such as INF uscire, 1SG.PST.IPFV uscivo, etc., has been explained by appeal to a semantic crossing with the lexeme uscio 'door', which has invaded the paradigm of the verb 'go out, exit', since 'one goes out through the door', as someone put it. But one goes out through the door even in the singular present indicative, or in the third plural, and yet these forms retain / $\varepsilon /$ : 1SG.PRS /' $\varepsilon$ sko/, 2SG.PRS /' $\varepsilon \iint 1 /$, 3PL.PRS /' $\varepsilon s k o n o /$, etc. Maiden observes that $/ \varepsilon /$ is retained precisely in the cells that belong to an independently established morphomic partition present in Italian verb paradigms, therefore constituting evidence for the "diachronic moulding force" exerted by such partitions even in a case of such extreme "irregularity" as stem suppletion resulting from incursion.

\section{Final remarks}

It seems to me that in Starke's model there is no place for morphomic effects in paradigms, such as those described in 4. In his account, the distribution of suppletive stems such as French /sav/ and /saf/ 'know' descends from the stipulated lexical meaning of such stems (one incorporating the $\mathrm{T}$ head and one stopping at the Md head), and does not relate to general abstract (and morphomic) properties of French verb paradigms.

Another aspect of Starke's analysis that I wish to comment upon is his use of "Last-resort movement" to shuffle heads inside trees in order to derive the desired content of lexical items: it seems to me that resorting to such movements is as arbitrary as accepting the existence of arbitrary morphomic partitions that govern the distribution of stems in paradigms. I have reported evidence, based on Maiden's work, for the psychological reality of morphomic partitions; it is not clear to me (but this might be entirely due to my inexperience in nanosyntax) what the evidence for the existence of last-resort movement is.

I have used up most of the space allowed for my contribution, and I cannot discuss other topics that point to the need for non-lexical models of morphology; I refer the interested readers to chapter 1 of Stump (2001), to Anderson (2015), and to a brief presentation in Thornton (2019).

I will finish by posing a specific question concerning Starke's analysis of French verbs. At minute 17:34 it is said that no lexical item has the sequence [\#[T ...]] in it ("none of the lexical items down here has number and $\mathrm{T}$ as their lower layers"); therefore, a derivation containing this sequence crashes, and must be rescued by "Last-resort movement", that moves the T head to the left of the \# head. However, the lexical item $\varepsilon$ introduced at minute 19:44 does contain exactly the sequence $[\#[\mathrm{~T} \ldots]]$ in the lowest layers of its tree. It is unclear to me why the derivation would crash at minute 17:34 for lack of a lexical item matching it, if this lexical item does indeed exist, since it comes up a few minutes later. I can understand that this item $\varepsilon$ was not introduced earlier in the talk for expository reasons, but it should be present in the mental lexicon of a mature French speaker at the same time in which $\tilde{o}, e, \partial$ and $i$ are present -- so the derivation shown at minute 17:34 should not crash, in my view. I am very interested in knowing what I have missed: that might explain why the crash would happen. 


\section{Acknowledgments}

I thank Stephen Anderson, Mark Aronoff, Olivier Bonami, Chiara Cappellaro and, above all, Martin Maiden for commenting on a first draft of this paper. Not all their suggestions could be taken up, in order not to exceed a reasonable space limit, and I am solely responsible for any shortcoming.

\section{References}

Anderson, Stephen R. 1982. Where's Morphology? Linguistic Inquiry 13: 571612.

Anderson, Stephen R. 1992. A-Morphous Morphology. Cambridge, UK: Cambridge University Press.

Anderson, Stephen R. 2015. The morpheme: Its nature and use. In M. Baerman (ed.), The Oxford Handbook of Inflection, 11-33. Oxford: Oxford University Press.

https://doi.org/10.1093/oxfordhb/9780199591428.013.2

Aronoff, Mark. 1994. Morphology by itself: stems and inflectional classes. Cambridge, MA: The MIT Press.

Bonami, Olivier, \& Gilles Boyé. 2003. Supplétion et classes flexionnelles dans la conjugaison du français. Langages 152: 102-126.

https://doi.org/10.3406/lgge.2003.2441

Bonami, Olivier, \& Gilles Boyé. 2007. Remarques sur les bases de la conjugaison. In E. Delais-Roussarie \& L. Labrune (eds.), Des sons et des sens, 77-90. Paris: Hermès.

Bonami, Olivier, Boyé, Gilles \& Françoise Kerleroux. L'allomorphie radicale et la relation flexion-construction. In B. Fradin, F. Kerleroux \& M. Plénat (eds), Aperçus de morphologie du français, 103-125. Saint-Denis: Presses de l'Université de Vincennes.

Hockett, Charles F. 1954. Two Models of Grammatical Description. Word 10: 210-231.

Maiden, Martin. 1992. Irregularity as a determinant of morphological change. Journal of Linguistics 28: 285-312.

https://doi.org/10.1017/s0022226700015231

Maiden, Martin. 1995. A proposito dell'alternanza ESCE, USCIVA in italiano. Lingua Nostra 56: 37-41. 
Maiden, Martin. 2004. When lexemes become allomorphs - On the genesis of suppletion. Folia linguistica 38: 227-256.

https://doi.org/10.1515/flin.2004.38.3-4.227

Maiden, Martin. 2018. The Romance Verb: morphomic structure in diachrony. Oxford: Oxford University Press.

Maiden, Martin, Smith, John Charles, Goldbach, Maria \& Marc-Olivier Hinzelin (eds.). 2011. Morphological Autonomy: Perspectives from Romance Inflectional Morphology. Oxford: Oxford University Press.

Matthews, P.H. (1991). Morphology. Second edition. Cambridge, UK: Cambridge University Press.

Pirrelli, Vito \& Marco Battista. 2000. The paradigmatic dimension of stem allomorphy in Italian verb inflection. Rivista di linguistica 12: 307-380.

Stump, Gregory T. 2001. Inflectional morphology. A theory of paradigm structure. Cambridge, UK: Cambridge University Press.

Thornton, Anna M. 2019. Theories of morphological analysis: a mini-review. In S. Sulpizio, L. Barca, S. Primativo \& L. S. Arduino (eds.), Word recognition, Morphology and Lexical reading: Essays in Honour of Cristina Burani, 158-166. London: College Publications. 